\title{
Lobular Capillary Hemangioma of Labial Frenum
}

(Maj) Devendra Srivastava', (Col) Shreehari A K² (Maj) Raghavendra $\mathrm{M} \mathrm{H}^{3}$, (Wg Cdr) P Kinra ${ }^{4}$

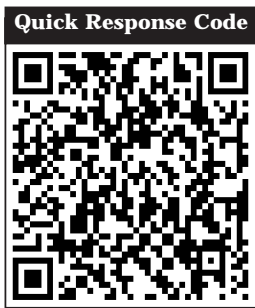

doi: 10.5866/2014.621567

${ }^{1}$ Resident,

Division of Periodontology, AFMC, Pune

${ }^{2}$ Associate Professor

Department of Dental surgery, AFMC, Pune

${ }^{3}$ Resident

Department of Dental surgery, AFMC, Pune

${ }^{4}$ Associate Professor

Department of Pathology, AFMC, Pune

\section{Article Info:}

Received: J anuary 13, 2014

Review Completed: February 10, 2014

Accepted: March 11, 2014

Available Online: J uly, 2014 (www.nacd.in)

C NAD, 2014 - All rights reserved

\section{Email for correspondence:}

drdeven11@gmail.com

\begin{abstract}
:
Pyogenic granul omas and hemangiomas are well-known benign lesions of the oral cavity. Pyogenic granuloma shows a striking predilection for the gingiva whereas Iobular capillary hemangioma is commonly seen in lip, cheek, and tongue, labial frenum occurrence of theselesions is extremely rare. The dinical diagnosis of such an uncommon occurrence is quite challenging as they sometimes mimic more serious lesions such as malignancies. The purpose of this article is to report an unusual case of a growth on labial frenum which was clinically diagnosed as fibroma (traumatic) and histopathologically as Iobular capillary hemangioma.
\end{abstract}

Key words: Lobular Capillary Hemangioma, Labial Frenum.

\section{INTRODUCTION}

Lobular Capillary hemangioma is a benign vascular tumor of the oral cavity which resembles pyogenic granuloma. ${ }^{1,2}$ Pyogenic granuloma also is a form of Iobular capillary hemangioma on the basis of histology but it shows a striking predilection for gingiva whilethelatter affect thelip, buccal mucosa or thetongue. ${ }^{3}$ Theclinical diagnosis of these lesions can be quite challenging as they sometimes mimic more serious lesions of malignancies.
Hemangiomas are benign malformations of blood vessels and are classified on the basis of their histological appearance as capillary, mixed cavernous or a sclerosing variety that has tendency to fibrose. ${ }^{4}$ Hemangiomas have a prevalence of 4$10 \%$ in Caucasian new born with 3 to 5 fold increase incidence in females. ${ }^{5}$ However the incidence in Indian population is unclear. The differentiation between a capillary hemangioma and pyogenic granuloma is somewhat unclear at this time. The purpose of this article is to report an unusual case 
of growth affecting the labial frenum which was diagnosed histopathologically as lobular capillary hemangioma.

\section{Case report}

A 20 years old female reported to the OPD of Department of Dental surgery, AFMC with the chief complaint of small growth on thelateral side of labial frenum since 15 days (Figure1). On eliciting the history, she noticed a small growth on the lateral side of labial frenum and she did not give any history of pain, pus discharge or bleeding from the lesion.

On examination, the lesion on the labial frenum was a well demarcated reddish pink, pedenculated growth with irregular margin of approximately 0.6 $x 0.5 \mathrm{~cm}$ size present on the left lateral side of labial frenum. The lesion was non tender, soft in consistency and there was no pulsation. It gave an initial impression of traumatic fibroma, which may have been caused by inadvertent tooth brush trauma.

An excisional biopsy was done after investigations including routine hemogram and urine examination. Excision of the lesion was done under local anesthesia (2\% lignocaine hydrochloride with adrenaline). The excised lesion was transported in $10 \%$ formalin for histopathological examination to Department of Pathology. Cap Amoxycillin 500 $\mathrm{mg}$ and Ibuprofen $400 \mathrm{mg}$ t.i.d. along with $0.2 \%$ chlorhexidine mouthwash were prescribed for 5 days during the post-operative period and sutures were removed 7 days post operatively. On review, the lesion showed uneventful healing after seven days. But after three weeks patient returned to the department following recurrence of the lesion in the same site (Figure 2). The case was taken up for excision of the recurrent lesion along with labial frenectomy (Figure 3 ). This time there was uneventful healing and the case was followed up for a period of 6 months and no recurrence was observed.

Both the histopathological findings revealed features of surface ulceration, acanthotic epidermis with focal areas of inflammatory infiltration predominantly neutrophils, with increased number of small vessels arranged back to back and feeding into larger vessels. The vessels were lined by single layer of normal endothelial lining. No cell atypia / malignancy were seen thus having a classical histological feature of Iobular capillary hemangioma (Figure 4).

\section{DISCUSSION}

Various lesions that mimic the presentation as in the present case include traumatic fibroma, fibro epithelial polyp, pyogenic granuloma and peripheral giant cell granuloma. ${ }^{6}$

The present case diagnosed as Lobular Capillary Hemangioma (pyogenic granuloma) is a prol iferative vascular lesion often clinically confused with hemangioma. The common sites for this lesion include lip, oral mucosa, tongue and nasal cavity. ${ }^{2}$ It may be difficult to make a light microscopic differentiation between a true hemangioma of infancy and a lobular capillary hemangioma. However, lobular capillary hemangioma exhibits immune cytochemical and ultrastructural differences. It is predominantly perithelial, rather than an endothelial tumour. ${ }^{5}$

The classification of hemangiomas is based on histopathological appearance. Therefore histopathological assessment remains the most accurate and satisfactory means of diagnosis. ${ }^{4}$ Radiographs are advised to rule out any bony destruction suggestive of hemangioma of central variety, malignancy or to identify a foreign body that needs removal along with the lesion.

Most small capillary hemangiomas like the one in the present case are usually treated with excision, but in case of central hemangiomas of jawbone or intraosseous hemangiomas, ligation of one or more of the major arteries may not arrest hemorrhage in the area of surgery because of rich collateral circulation. Such cases can be treated more conservatively with embolization and sclerosing agents. Other treatment modalities consist of ligation and excision, artificial ulceration, electrolysis and thermocautery, sclerosant therapy, radiation and compression depending on the clinical features and the anatomic considerations. ${ }^{7}$

\section{CONCLUSION}

Capillary hemangiomas are infrequently and rarely seen on the labial frenum and may easily be confused with a variety of different lesions particularly with chronic traumatic lesion such as fibroma. A proper diagnosis of the lesion is mandatory before planning for a successful treatment modality. Histopathological assessment remains the most accurate and correct mode of investigation for such oral lesions. 


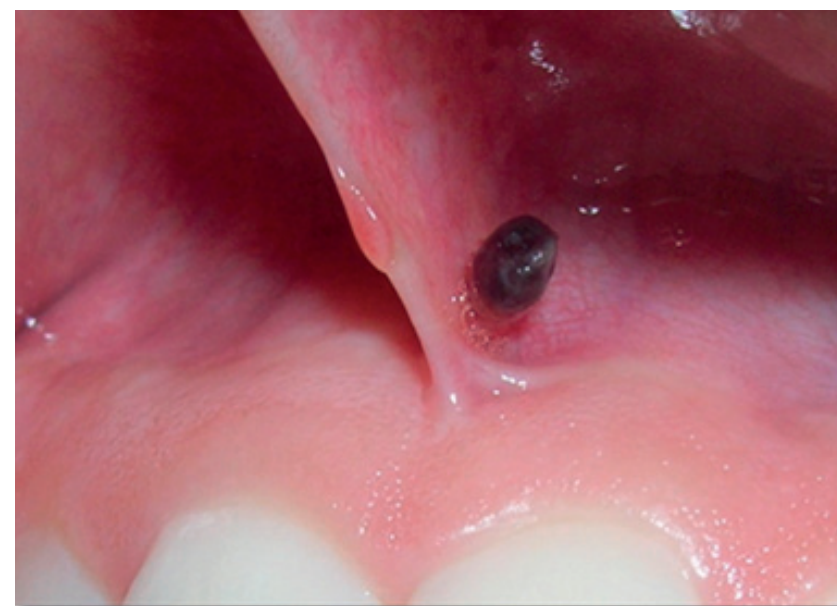

Figure 1: Intraoral clinical picture showing growth on labial frenum.

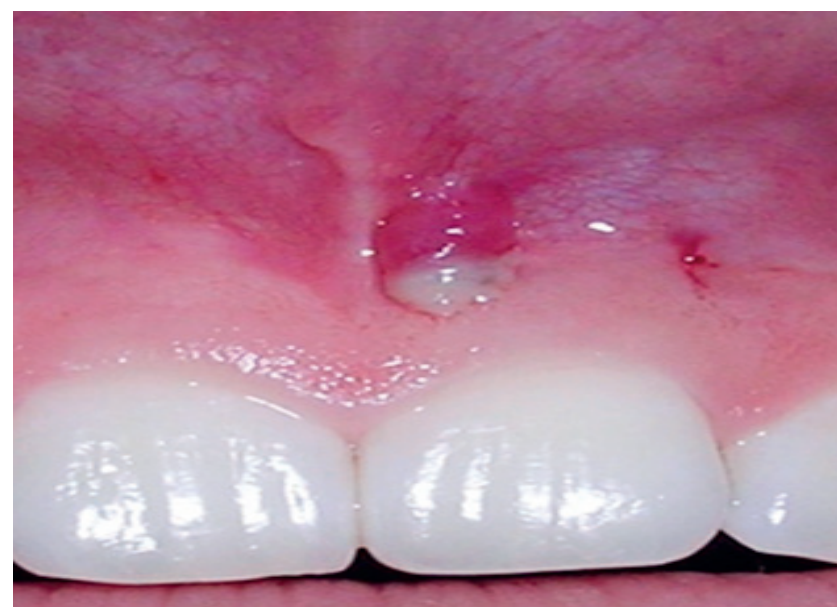

Figure 2: I ntraoral picture showing recurrence after 15 days

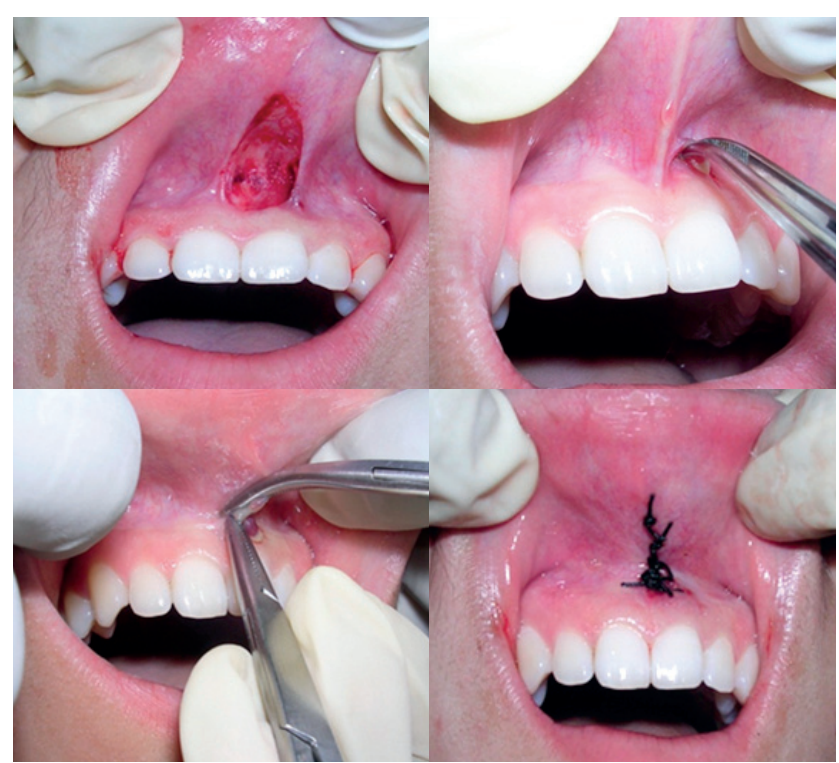

Figure 3: Excision of the lesion along with labial frenectomy

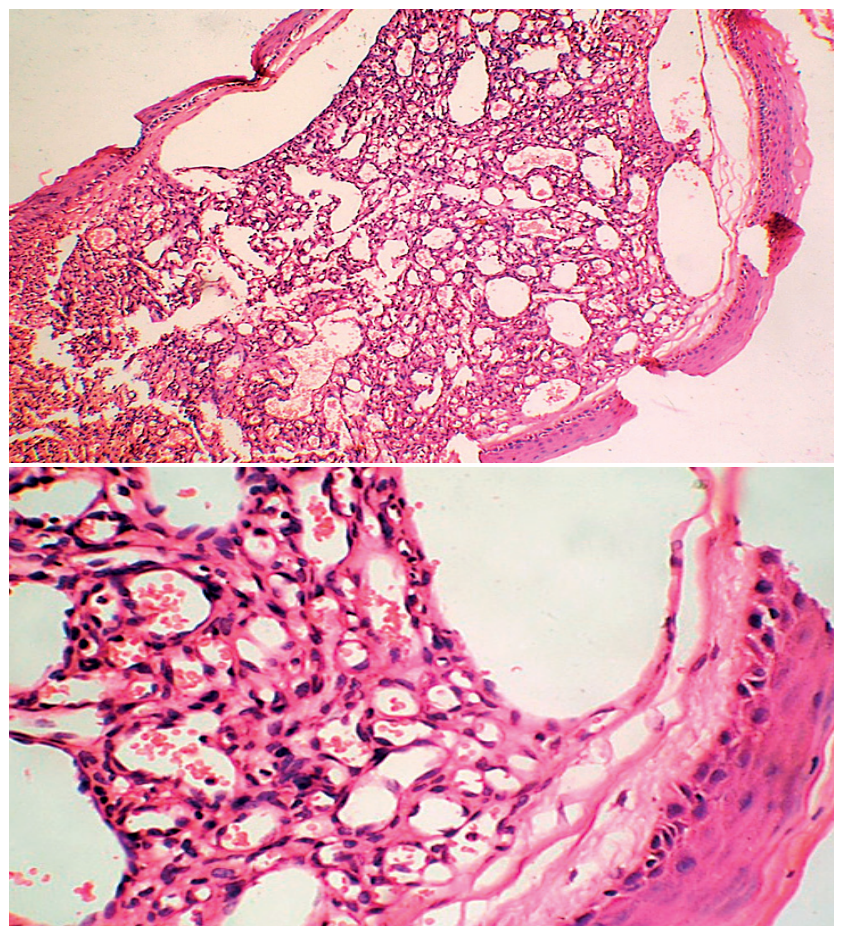

Figure 4: $\mathrm{H}$ and $\mathrm{E}$ section shows features of surface ulceration, acanthotic epidermis with focal areas of inflammatory infiltration predominantly neutrophils, with increased number of small vessels arranged back to back and feeding into larger vessels. The vessels were lined by single layer of normal endothelial lining (10X and 40X).

\section{REFERENCES}

1. Kumar V, Abbas A, Fausto N, Aster J .Robbins and Cotran Pathologic Basis of Disease 7th ed. Philadelphia, Pa: Elsevier Inc 2004:511-554.

2. Shafer WG, HineMK, Levy BM. A Textbook of Oral Pathology. 4th ed. Philadelphia: WB Saunders; 1983: 359-360

3. Patil K, Mahima VG, Ambika L. Extragingival pyogenic granuloma. Indian J Dent Res. 2006; 17:199-202.

4. Acikgoz A, Sakallioglu U, Ozdamar S, Uysal A. Rare benign tumours of oral cavity - capillary haemangioma of palatal mucosa: A case report. Int J Paed Dent. 2000; 10:161-165.

5. Mulliken J B. Cutaneous Vascular Anomalies. In: Mccarthy J G, editor. Plastic Surgery: Tumors of Head and Neck and Skin. Vol. 5. Philadel phia: B Saunders Company Ltd; 1990:3194-3230.

6. Wood NK, Goaz PW. Differential diagnosis of oral and maxillofacial lesions. 5th Ed. Missouri: Mosby; 1997:549550.

7. Greene LA, Freedman PD, Friedman J M, Wolf M. Capillary hemangioma of the maxilla. Oral Surg Oral Med Oral Pathol. 1990; 70:268-273. 